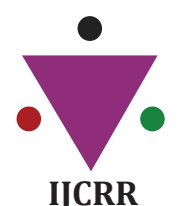

Section: Healthcare Sci. Journal Impact Factor: 6.1 (2018) ICV: 90.90 (2018)

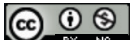

Copyright@IJCRR

\section{Experience of Prescription Audit of Drugs Prescribed in Outpatient Attendees of Private Teaching Hospitals in Central India}

\author{
Shadma Quazi ${ }^{1}$, Sushil Kumar Varma ${ }^{2}$, Sharjeel Khan ${ }^{3}$, B R Singh ${ }^{4}$, Sarju Zilate ${ }^{5}$

\begin{abstract}
'Assistant Professor, Dept. of Pharmacology, DattaMeghe Medical College, (DattaMeghe Institute of Medical Sciences) Wanadongri, Hingna, Nagpur, Maharashtra, India; 'Professor and Head Dept. of Pharmacology, Mahatma Gandhi institute of medical sciences and research centre, Sewagram, Wardha, India; ${ }^{3}$ Assistant Professor, Dept. of FMT. Datta Meghe Medical College, (DattaMeghe Institute of Medical Sciences) Wanadongri, Hingna, Nagpur Maharashtra, India; 4Professor and HOD, Dept. of Anatomy, Datta Meghe Medical College, (DattaMeghe Institute of Medical Sciences) Wanadongri, Hingna, Nagpur Maharashtra, India; ${ }^{5}$ Assistant Professor, Department of Pharmacology, Jawaharlal Nehru Medical College, (DattaMeghe Institute of Medical Sciences) Sawangi Wardha, Maharashtra, India.
\end{abstract}

\title{
ABSTRACT
}

Background: Prescription audit assists us in tracking, reviewing and recommending improvements in management practices required to increase the consistency of approved products. Our mission was to conduct prescription audits of drugs prescribed in outpatient attendees and their effect on improvements in quality in future.

Methods: During august 2019-July 2020 the present cross-sectional analysis, was carried out to assess the utilization of drugs and their prescribing pattern. Total of 100 prescriptions was collected, reviewed and analyzed with statistical effect using several advising precise indicators (acclaimed by the World Health Organization). Area of development was identified, the mindful attempt was put in and after two weeks of delay, there was improved care efficiency. The investigation and statistically comparison with the first set was done with a collection of 100 more prescriptions.

Results: The prescription audit assessment of the total patients in 200 patients revealed that five parameters, including Generic Drug Name (16/100) dose (84/100), Total medication number required (00/100), patient's address (00/100), Legibility of Prescription (100/200), are weak in the first set of 100 prescriptions using 18 parameters prescripted in WHO core prescription factors. The results of the above-listed improvement of five parameters as generic drug names (100/100), medication dosage (88/10), Total number of medicines required (100/100), address of patients, legibility of prescription (176/100), and resulted in improved quality of prescriptions.

Conclusion: Our study advocated on overall rational utilization of drugs. Through prescription audit process we can improve patient care, essentially imitate and assess the worth of prescribing activities and practice, helping to identify the changes required to get a better prescription for patient centre managing.

Key Words: Prescription Audit, Drug Utilization, WHO prescribing factors, medication dosage, Generic Drug

\section{INTRODUCTION}

The trends of drug usage have been quite troubling in recent years. ${ }^{1}$ A prescription is written correspondence from a physician to a pharmacy about guidance on medication dispense. Auditing a prescription is the method of increasing the quality of patient care. ${ }^{2}$ The level of patient care is routinely and scientifically evaluated. The audit is also a method that regularly examines the care of patients. For physicians, patients and the public, a good prescription audit is essential.
It also provides doctors with the best treatment for their patients. This provides the best performance analysis, describing criteria as per the drug audit checklist. By increasing medical conditions at the primary levels of the healthcare system, the quality of life may be improved. The compliance with these requirements is checked by a prescription audit. ${ }^{3}$

The audit is remarkably important for the accuracy of the prescriptions administered by clinicians, as poor prescribing practices contribute to ineffective and benign care that

\section{Corresponding Author:}

Dr. Sharjeel Khan, Assistant Professor, Department of FMT, Datta Meghe Medical College, (Datta Meghe Institute of Medical Sciences), Wanadongri, Hingna, Nagpur Maharashtra, India; Email: quazi18shad@gmail.com

ISSN: 2231-2196 (Print)

Received: 22.06 .2020
ISSN: 0975-5241 (Online)

Revised: 24.07 .2020
Accepted: 14.08 .2020 
exacerbates or prolongs illness and harms a patient, adding a further burden on health budgets. ${ }^{4}$

The rationality of the scripts prescribed by physicians is of critical importance, Since poor prescribing habits lead to inadequate and unsafe care, exacerbating or prolonging the disease and causing patient discomfort or damage, which adds an extra burden to health budgets. ${ }^{4}$

The audit is generally defined as a healthcare incident analysis and evaluation and recording to relate the quality of the treatment received to the agreed standards. ${ }^{5}$ The prescription records are the key method used to administer medicines. The drug audit is the portion of the audit that helps to track, evaluate and recommend corrections procedures for practitioners wherever appropriate. ${ }^{6}$ Several differences are found in the prescriptions, though most of them contain fundamental paragraphs. ${ }^{7}$

The basic rules for reasonable prescribing, before any prescription is written, depending on the knowledge of a history of the clinical and pharmaceutical procedure, including prior adverse events; diagnosis; specific patient and medical conditions, which may influence medicinal effects, such as pregnancy, renal and hepatic disease and experience with prescription drugs. For all of these fields, complexity is likely to increase the likelihood of unexpected outcomes. ${ }^{7}$

Medical audit oversees the observance in quality of requirements of Medical treatment at all levels of the delivery system of health care. The prescribing pattern analysis is a portion of a medical audit to track, assess and adjust prescription practice to achieve fair and cost-effective medical procedures. ${ }^{8}$

World Health Organization (WHO) proposed essential prescribing indicators for prescription audit and drug use studies. The focus of Indian studies ${ }^{9-12}$ has mainly been on the WHO prescribing indicators such as the variety and amount of drugs per prescription..$^{13}$ Besides, some kind of examination, documentation and analysis of their performance, diagnosis and care have also been coordinated by the best clinicians. We often used to call it an audit. Before explaining the concept on which its meaning is based, it would not be right to describe medical audit. Nevertheless, the medical audit is described as the evaluation of medical care quality by the retrospective review of the medical records to understand the matter easily. ${ }^{14,15}$ This research focuses on the nature and volume of medications used and the prescription habits of doctors in a private teaching hospital in Maharashtra. This is the first research of this kind in this area, to the best of our knowledge. The research aimed to enhance the quality of health care by highlighting differences in physician prescribing practices and offering a potentially more reliable and cost-effective use of drugs ${ }^{16}$ and to find out the rationality. ${ }^{17}$

\section{MATERIALS AND METHODS}

The study was conducted after the approval from IEC.

It was a prospective cross-sectional observational analysis.

\section{STUDY SETTING}

This study was carried out at outpatient attendees of private teaching hospitals in central India.

Subjects getting medication throughout treatment were included and studied.

Duration of study the period is from August 2019 to July 2020.

This audit report reveals how well we compose regulations.

A successful medication is written and has relevant facts as provided (Internationally agreed criteria) by the World Health Organisation .

1. Prescriber title

2. Prescriber's code

3. Date: Date

4. Drug name-(generic or not user name) brand name

5. Medicine power

6. Dose-How much? How much?

7. Dosage-How much a day?

8. Dosage-How long?

9. Specific instructions (e.g. after food)

10. Complete amount of tablets or syrup, dispensing pharmaceutical

11. Patient's name

12. Patient Address

13. Patient's Age

14. Legibility (scale of 0 to 2 - 0 - Illegible, 1 - Just legible, 2 Perfect)

15. Amount of prescription drug products

16. Amount of prescription combination medicines

17. Amount of approved antibiotics

18. The total recommended number of injections ( 1 a day is 5 injections for 5 days)

\section{Criteria of Inclusion:}

Patients who attended the clinic have prescription papers.

The research included both male and female patients

\section{Criteria for Exclusion:}

The removal of patients who do not require any drugs.

\section{Inpatients}

Patients with less than 2 drugs in the prescription

Patients attending OPD for injections. 


\section{METHODOLOGY TO IDENTIFY CHANGES ${ }^{16}$}

1. Carbon paper was used to produce a copy each day for 10 days of 10 random prescriptions,

2. 100 prescriptions in all.

3. A member of the investigative team reviewed and analysed the collected prescriptions using the excel sheet. a. For every item, mark 1 or 0 (1-13),

b. Label 0,1 or 2 to read the text as quickly as possible (item 14)

c. Each item's numbers (15-18).

4. Once this data has been entered, add total and percentage or average
a. Of the $50(1-13$ items $)$
b. $\quad$ Of hundred (14 items)
c. Median (15-18 items)

5. The rate for the results appraisal for each of the parameters tested.

6. Performance evaluated by $95 \%$ (for items 1-14) Norm.

7. Recognized areas for change

\section{Methods for Implementation of modifications:}

1. These changes have been implemented through increased time allocation and conscious effort.

2. After 2-3 weeks, the cycle is begun again and collected data for 100 more prescriptions.

3. As in the first round of audits, analyses were conducted.

4. Analysed and compared to progress in the first round.

\section{OBSERVATIONS AND RESULTS}

The present study was undertaken in the Dept. of Pharmacology at Datta Meghe Medical College, Shalinitai Meghe Hospital and Research Centre, Nagpur in collaboration with Jawaharlal Nehru Medical College, Datta Meghe Institute of Medical Sciences, Sawangi (Meghe), Wardha.

Table 1: Showing the WHO Core Indicators with their values/averages in Set I of prescription.

\begin{tabular}{llc}
\multicolumn{3}{c}{ Table 1: Set I of Prescription } \\
WHO Core Indicators with their values/averages in Set I \\
S No & Observed Parameters & Scores /average \\
1. & Prescriber 's Name & $100 / 100$ \\
2. & Prescriber 's code & $100 / 100$ \\
3. & Date: Date & $100 / 100$ \\
4. & Drug name-(the generic name & $16 / 100$ \\
& used or not) drug name \\
5. & Medicine power \\
6. & Dose-How much? How much? & $84 / 100$ \\
7. & Dosage-How much a day? & $100 / 100$ \\
8. & So many days is the dosage? & $100 / 100$
\end{tabular}

9. $\quad$ Additional instruction (e.g. $\quad 100 / 100$ after meals)

10. Total tablet/syrup number, $\quad$ oo/100 pharmacy to be dispensed

11. Patient's Name 100/100

12. Patient Address $00 / 100$

13. Patient's Age 100/100

14. Readability (o to 2-o - Unread- 100/200 able, 1 - Readable, 2 Perfect)

15. Number of medicinal products 1(average) in prescription

16. Number of prescription combi- o(average) nation medicines

17. Number of antibiotics pre- o(average) scribed

18. Total injection number pre- o(average) scribed in the prescription

Table 2: Showing the WHO Core Indicators with their values/averages in Set II of prescription.

\section{Table 2: Set II of Prescription}

WHO Core Indicators with their values/averages in Set II

S No Observed Parameters Scores /average

1. Prescriber 's Name 100/100

2. Prescriber 's code 100/100

3. Date: Date 100/100

4. Drug name-(the generic name 100/100 used or not) drug name

5. Medicine power 100/100

6. Dose-How much? How much? 88/100

7. Dosage-How much a day? 100/100

8. So many days is the dosage? $100 / 100$

9. Additional instruction (e.g. after 100/100 meals)

10. Total tablet/syrup number, phar- $\quad$ oo/100 macy to be dispensed

11. Patient's Name 100/100

12. Patient Address 0o/100

13. Patient's Age 100/100

14. Readability (o to 2-o - Unread- 172/200 able, 1 - Readable, 2 Perfect)

15. Number of medicinal products in $\quad 1$ (average) prescription

16. Number of prescription combina- $\quad$ 1(average) tion medicines

17. Number of antibiotics prescribed 1(average)

18. Total injection number prescribed 1(average) in the prescription 


\section{Areas of changes identified:}

In analysing the first set with 100 prescriptions using 18 prescription factors prescribed by the World Health Organization, five parameters were found to be poor, such as Generic Name of Medicine (16/100), Drug Dosage (84/100), Total drug requirements $(00 / 100)$, Patient address $(00 / 100)$, Legibility of prescription (100/200) (table no 1).

The above five parameters seem to have improved by the Generic Drug Name (100/100), Drug Dosage (88/100), Maximum medication requirement (100/100), Patient's address (100/100), Readability of prescription (172/200). Conscious attempts were made to increase the consistency of prescription in the second set. Hence resulting in improved quality of patient care (table no 2).

\section{DISCUSSION}

The medical audit is the critical check as the vision for the medical and health care system to achieve crucial improvement in the quality of the healthcare offered to patients. ${ }^{18}$ The prescribing behaviours are crucial because the clinical efficacy and protection lie solely in the logic of the prescriptions. $^{19}$

Prescription auditing is among an ideal tool for preventing drug abuse and to propose rational drug use. More than 50 per cent of the patients have miscarried their own drugs, and it is estimated that over half of the medications are administered and dispensed incorrectly. ${ }^{7}$ Furthermore, a recent study with similar designs to ours has shown how easy and effective a feedback system is important to prescribe ${ }^{20}$. If the bad skills in the prescription are habitual zed, it is more difficult for them to improve in post-graduate life and typically require a variety of costly and time-consuming training strategies ${ }^{21-27}$. Auditing scripts and getting input on medications may be a helpful way to improve physician prescribing behaviour. ${ }^{28-37}$

\section{Occasions of irrational use of drugs include:}

1. Polypharmacy - A community-based prescription design study carried out from retail stores in India reported an average of two prescription drugs ${ }^{38,39}$ like ours. Other studies conducted by hospitals in India reported 3-5 prescription drug figures ${ }^{40-42}$

2. Inadequate dosage,

3. The use of antimicrobials even for infections without bacteria;

4. Extreme use of injections wherein available oral forms and

5. Nonconformitytotreatingregimens. ${ }^{43}$

\section{Parameters reviewed in the examination of prescription}

The best criteria for the drug audits to be discussed are,

\section{Demographics of patients}

a) Name Title

b) Gender

c) Age

d) Weight of body

e) Prescription date

\section{Medical diagnosis:}

\section{Standards for prescription}

a) Dose.

b) Type of dosage.

c) Name in pharmacology

d) Name of the company manufactured the drug- The explanations for using brand names should be understood (such as comfortability with brand names, the opinion that generic drugs are of low quality, etc.) and addressed with appropriate interventions. ${ }^{13}$

e) Duration of treatment

f) Time of administration

\section{Name and signature of doctors}

\section{Superscription (demographic) details:}

The date of the prescribed superscription shall include patient name, address, weight and age; and the Rx. The "Rx" symbol is called an ellipse for the Latin term, meaning that a pharmacist who was previous to the "recipe" of a physician for the preparation of a drug ${ }^{2}$ is "taken" or "taken thus." Name and address of the patient are required to ensure the proper medicine goes to the right patient on the prescription. The weight, age, or surface of a patient should be noted on the prescription 7 in the dosage calculation.

This value is negligible when compared to the study conducted by Sirisha et al. ${ }^{19}$

\section{Clinical Diagnosis}

A diagnosis based not on diagnostic tests but clinical signs and symptoms.

The delivery of quality treatment is influenced by clinical diagnosis?

\section{Standards for prescription:}

Dose, dosage size, pharmacologic name, brand name, length, time of administration are all aspects of medication. The prescription requirements must be met by the medication guidelines that lead to reasonable prescribing. Weak handwriting is a common and remedial source of errors therefore legibility is essential. ${ }^{2}$ Several medication errors have been held responsible for illegible writing of the prescriber. Illegible writing creates uncertainty and can potentially lead to dispensing of wrong drugs which can result in serious adverse events and even death..$^{44,45}$ 


\section{Name and Signature of Doctors}

Name, address and qualification of the doctor. This ensures that controlled drug prescriptions contain the physician's name, address and registration number. ${ }^{11}$ Some non-full prescriptions are one of the disadvantages and raise chance treatment errors. ${ }^{46}$

\section{WHO prescription indicators}

A study of the different prescription indicators can understand the doctor's presentation regarding drugs. The criteria that can be used in the research are focused on the clinical procedures observed. These indicators can either be retrospectively examined, from data recorded in patient records or made in the future. Similar publications from foreign papers have been reviewed to test if the requirements of prescribing have been complied with. Such research found that most doctors did not value the diagnosis and use of medication in writing. ${ }^{47}$

In our research set I of 100 prescriptions based on 18 criteria recommended by core WHO variables found that 5 criteria, such as the generic drug name (16/100), the drug dose $(84 / 100)$, the total number of required drugs $(00 / 100)$, patient address (00/100), the readability (100/200) were low. The analysis showed that the medication is inappropriate for usage. The attempt was made, however, to enhance the consistency of the prescriptions during round II. The time had been increased for each prescription and the final results, the above five criteria seemed to have improved outcomes as the drug generic name (100/100), the drug dosage (88/100). Total number of medicinal products required (100/100), patient's address (100/100), prescription legibility (172/200).

While readability and dosage of the medication have not improved by as much as to 100 per cent substantially from round I, increased attention will further increase the scores over the coming days. Ultimately, prescription audits are an auto-test tool that helps us to greatly correct our prescriptions by pointing out our errors. Such basic changes lead to better patient care ${ }^{7}$. Comparing the current use of medicines with the standard treatment guidelines will improve treatment effectiveness and make it cost-effective. ${ }^{13}$ Such audits are valued to generate and test the hypothesis that improper drug measures have been carried out to improve prescribing patterns ${ }^{47}$, the information can usefully be channelled into adverse drug reaction monitoring programs too. ${ }^{8,48}$

Two separate randomized controlled trials in Norway 49 and The Netherlands have reported similar changes in the treating behaviour of asthma and urinary tract infection by the physicians. ${ }^{50}$ Several related articles are available.$^{51-61}$

This Prescription Audit of Outpatient Attendees in our Hospital was a qualifying workout in the soul. Its chief aim was to deliver an unbiased basis namely, illness pattern and real use of drugs by the doctors, and helping in formulating an essential medicines list (EML) for the hospitals.

\section{CONCLUSION}

An audit is a tool that can be used to enhance patient treatment. It represents and measures, acknowledges judgmentally, the importance of prescription and procedure that assists in the assessment of modifications to improve health care prescription. Irrational, unsatisfactory treatment will cause patients unnecessary costs. Many of the patterns that are recommended are insightful and need attention. To order to develop pharmacy procedures, the importance of drug screening for development and testing of defective medication would certainly interfere with patient care. Our goal in creating this pharmaceutical audited was that the patient population attending the out-patient hospital would be reflected as accurately as possible, with minimal intervention in the performance of prescriber and hospital administrative duties.

The drop-outs, including the patients who went missing after a visit without a prescription and the patient who did not purchase medications from the hospital pharmacy, were not our accountability. Patients that were re-visited were still not adequately covered by prescriptions alone, because few of them did not have the hospital ambulatory code and were not counted.

We understand that if simultaneous data collection from the department of medical records has been initiated, all these sampling errors may be considered. Then, we could have tested for the significance of the relationship between age and prescribing prevalence for each category of drugs for both sexes as was done by Hurley et al. The current research may serve as a basis for examining the extent of the education intervention and changes in prescribing trends in the drug test.

\section{Acknowledgement: None}

Conflict of interest: None

\section{Source of Funding: None}

\section{REFERENCES}

1. Nacher M. Malaria vaccine trials in a wormy world. Trends Parasitology 2001; 17:563-5

2. Patel N, Desai M, Shah S, Patel P, Gandhi A. A study of medication errors in a tertiary care hospital. Perspectives in Clinical Research. 2016;7(4):168-173.

3. Curtis P. Medical audit in general practice. J R Coll Gen Pract.1974; 24(146): 607-11.

4. AhmetAkici, Zafer Go, CenkAypak, Berna TerzioguleOktay. Prescription audit adjunct to rational pharmacotherapy education improves prescribing skills of medical students. Eur. J Clin. Pharmacol. 2005; 61: 643-650

5. Patterson HR. The problems of audit and research. J R Coll Gen Pract. 1986; 36(286):196-202.

6. Srishyla M, Mahesh K, Nagarani M, Mary C, Andrade C, Venkataraman B. Prescription audit in an Indian hospital setting using the DDD (Defined Daily Dose) concept. Indian Journal of Pharmacology. 1994; 26(1):23-8. 
7. Yousuf Ali A S, Arun Kumar J, Dr Parthiban R. The study on the effect of self-auditing the prescriptions in a polyclinic.Int. J. of Res. in Pharmacology and Pharmacotherapeutics 2019; 8(2): 275-281.

8. M.V. Srishyla, Mahesh Krishnamurthy, M.A. Naga Rani, Sr. Mary Clare, C. Andrade*, B.V. Venkataraman. Prescription Audit In An Indian (Defined Daily Dose) Concept. Indian Journal of Pharmacology 1994; 26: 23 - 28

9. Biswas NR, Jindal S, Siddiquei MM, Maini R. Patterns of prescription and drug use in ophthalmology in a tertiary hospital in Delhi. Br J Clin Pharmacol. 2001; 51:267-9.

10. Schewade DG, Pradhan SC. Auditing of prescriptions in a government teaching hospital and four retail medical stores in Pondicherry. Indian J Pharmacol.1998;30:408-10.

11. Kshirsagar MJ, Langade D, Patil S, Patki PS. Prescribing patterns among medical practitioners in Pune, India. Bull World Health Organ. 1998;76:271-275.

12. Devi DP, George J. Diabetic Nephropathy: Prescription trends in tertiary care. Indian J Pharm Sci 2008; 70:374-8.

13. Hanumantha Rao Potharaju, S. G. Kabra Prescription audit of outpatient attendees of secondary level government hospitals in Maharashtra. Indian Journal of Pharmacology .2011; 43 (2):150156.

14. Joshi SK.Quality Control Study. In: Joshi SK, Quality Management in Hospitals. $2^{\text {nd }}$. Jaypee Brothers; 2008; 50: 7-11.

15. Sharma R, Mehta M. The textbook of NABH Guideline. 3, 2008, 100-125.

16. R K Rishi, K S Sharma, Sanqeeta M Tailang. Prescription audit: experience in Garhwal (Uttaranchal), India. Tropical Doctor April 2003, 33.76-79.

17. Nuthan Kumar U. S, Nalini G. K., Deepak P., Prema M., GeetaRathod, Mohith N. Prescription audit of outpatients in the tertiary care government hospital. International Journal of Basic \& Clinical Pharmacology. 2018; 7( 4): 636-639.

18. Bandyopadhyay D, Banerjee NC, Chattopadhyay S, Singha P. A Study of Prescription Auditing in a Tertiary Care Teaching Hospital of Eastern India.J Drug Deliv Ther. 2018;4(1):140-9.

19. Deepa Sunny, Kalyan Roy, Sherin Sara Benny, Dano C Mathew, JarupalaGangadharNaik, KarunakaranGauthaman.Prescription Audit in an Outpatient Pharmacy of a Tertiary Care Teaching Hospital-A Prospective Study J Young Pharm. 2019;11(4):417420.

20. Prystowsky JB, DaRosa DA. A learning prescription permits feedback on feedback. Am J Surg. 2003;185:264-267.

21. De Vries TPGM, Henning RH, Hogerzeil HV, Fresle DA, Guide to good prescribing. World Health Organization/ Action programme on essential drugs. WHO, Geneva. 1994.

22. Le Grand A, Hogerzeil HV, Haaijer-Ruskamp FM. Intervention research in the rational use of drugs: a review. Health Policy Plan. 1992;14(2):89-102.

23. Hogerzeil HV. Promoting rational prescribing: an international perspective. Br J Clin Pharmacol1995; 39:1-6.

24. World Health Organization. How to investigate drug use in health facilities: selected drug use indicators. World Health Organization, Geneva. 1993.

25. Laing RO, Hogerzeil HV, Ross-Degnan D (2001) Ten recommendations to improve the use of medicines in developing countries. Health Policy Plan 16(1):13-20.

26. Figueiras A, Sastre I, Gestal-Otero JJ. Effectiveness of educational interventions on the improvement of drug prescription in primary care: a critical literature review. J Evaluation Clinical. Pract. 2011; 7(2):223-241.

27. Akili A, Karaca S, Ugurlu MU, Oktay S. Prescribing habits of general practitioners in the treatment of childhood respiratory tract infections. Eur J Clin Pharmacol. 2004; 60(3):211-216.
28. Mugford M, Banfield P, Hanlon MO. Effects of feedback of information on clinical practice. BMJ1991; 303:398-402

29. Bates DW, Teich JM, Lee J, Seger D, Kuperman GJ, Ma'luf N et al (1999) The impact of computerized physician order entry on medication error prevention. J Am Med Inform Assoc 1999; 6:313-321

30. Donald JB (1986) Online prescribing by computer. BMJ 1986; 292:937-939.

31. Achcroft DM, Chapman S, Lockett J. Supporting the implementation of prescribing advice in PCOs. Pharm J. 2001; 267:558559.

32. Delesie L, Croes L (2002) Monitoring the variability in drug prescribing patterns: benchmarking and feedback in Belgium. Eur J Clin Pharmacol. 2002; 58:215-221.

33. Nilsson G, Hjemdahl P, Hassler A, Vitols S, Wallen NH, Krakau I. Feedback on prescribing rate combined with problem-oriented pharmacotherapy education as a model to improve prescribing behaviour among general practitioners. Eur J Clin Pharmacol. 2001; 56:843-848.

34. Simon GE, Vonkorff M, Rutter C, Wagner E (2004) Randomized trial of monitoring, feedback and management of care by telephone to improve treatment of depression in primary care. BMJ 320:550-554

35. Braybrook S, Walker R (2000) Influencing NSAID prescribing in primary care using different feedback strategies. Pharm World Sci. 2000; 22(2):39-46

36. Chardonnet C, Dufrene I, Davidian S, Hida H, Laurencin C. Evaluation of changing antibiotic prescription habits in a general hospital centre. Presse Med. 2001; 37:1821-1824.

37. Palmer NA, Diley YM. General dental practitioners' experiences of a collaborative clinical audit on antibiotic prescribing: a qualitative study. Br Dent J. 2002; 193(1):46-49

38. Hede SS, Diniz RS, Agshikar NV, Dhume VG. The pattern of prescribed and OTC drugs in North Goa. Indian J Pharmacol 1987:19:145-8.

39. Lee D, Bergman U. Studies of drug utilization. In: Strom BL, ed. Pharmacoepidemiology, 2nd edn. Philadelphia: John Wiley \& Sons, 1994:379-93

40. Kapoor B. Raina RK, Kapoor S. Drug prescribing pattern in a teaching hospital. Indian J Pharmacol 1985; 17( 1):168-173.

41. Kumar H, Gupta U, Garg KC, Agarwal KK. A study of the trend of drug usage in a hospital unit.Indian J Pharmacol 1986; 18:50.

42. Sood B. Verma RK. Gulati PV. Diagnosis and treatment in a general hospital.The Clinician 1984; 48:263-70.

43. Abidi A, Gupta S, Kansal S, Ramgopal.Prescription auditing and drug utilization pattern in a tertiary care teaching hospital of western UP. Int J Basic Clin Pharmacol. 2012; 1(3):184- 190.

44. Sikidar P, Chakravarty P.International Journal of Basic and Clinical Pharmacology. 2016; 5(3):975-982.

45. Pandey V, Hoda U. Evaluation of prescribing patterns in diabetic and hypertensive patients in a South Delhi Hospital. International Journal of Basic and Clinical Pharmacology. 2014;3(3).

46. Sirisha S, Shibi Mary Thomas, Anand Varghese, Rama Reddy, Benny Baby, Shreya P Gudur. A Descriptive Study on Prescription Audit in India-A Review. Indo Ame. J Pharma. Sci. 2015; 3(4): 641-647.

47. Hurley SF, McNeil JJ, Jolley DJ, Harvey R. Linking prescription and patient-identifying data: a pilot study. Med J Aust 1992; 156:383-6.

48. Shadma H. Quazi, Sushil K. Varma, Sharjeel H. Khan and et al. Hypersensitivityreactions to intravenous ferric carboxymaltose in a patient with iron deficiency anemia: arare case report. International Journal of Basic and amp; Clinical Pharmacology May 2018, 7(5):1036-1039. 
49. Lagerlov P, Loeb M, Andrew M, Hjortdahl P (2000) Improving doctors' prescribing behaviour through reflection on guidelines and prescription feedback: a randomised controlled study. Qual Health Care 2000; 9:159-165

50. Veninga CCM, Denig P, Zwaagstra R, Haaijer-Ruskamp FM (2000) Improving drug treatment in general practice. J Clin Epidemiol. 2000; 53:762-772.

51. Sharma, S.K., and K. Dheda. "What Is New in the WHO Consolidated Guidelines on Drug-Resistant Tuberculosis Treatment?" Indian Journal of Medical Research 2019; 149(3): 309-312.

52. Chhabra, K.G., A. Sharma, C. Chhabra, J.J. Reddy, S.G. Deolia, and Y. Mittal. "Knowledge, Attitude, and Practices Regarding Pharmacovigilance and Adverse Drug Reaction Reporting among Dental Students in a Teaching Hospital, Jodhpur, India: A Cross-Sectional Study." Journal of Contemporary Dental Practice. 2017; 18, (10): 964-69.

53. Ghangurde, A.A., K.K. Ganji, M.L. Bhongade, and B. Sehdev. "Role of Chemically Modified Tetracyclines in the Management of Periodontal Diseases: A Review." Drug Research . 2017; 67(5): 258-65.

54. Sharma, S.K., J. Chaubey, B.K. Singh, R. Sharma, A. Mittal, and A. Sharma. "Drug Resistance Patterns among Extra-Pulmonary Tuberculosis Cases in a Tertiary Care Centre in North India." International Journal of Tuberculosis and Lung Disease.2017; 21(10): 1112-1117.

55. Dhar, R., S. Singh, D. Talwar, M. Mohan, S.K. Tripathi, R. Swarnakar, S. Trivedi, et al. "Bronchiectasis in India: Results from the European Multicentre Bronchiectasis Audit and Research Collaboration (EMBARC) and Respiratory Research
Network of India Registry." The Lancet Global Health. 2019; 7(9): e1269-79.

56. Jain, V., L. Waghmare, T. Shrivastav, and C. Mahakalkar. "SNAPPS Facilitates Clinical Reasoning in Outpatient Settings." Education for Health: Change in Learning and Practice. 2018; 31(1): 59-60.

57. Aglawe, P.B., R.K. Jha, V. Mishra, K.M. Sakore, A. Chetan, and D.S. Shrivastava. "Appraisal of Core Therapy, Supportive Therapy, and Alternative Therapy in a Tertiary Care Rural Hospital of Vidarbha Region in Correlation to Plethora of Menopausal Problems." Journal of Mid-Life Health 2019; 10(1): 14-21.

58. Bhayani, P., R. Rawekar, S. Bawankule, S. Kumar, S. Acharya, A. Gaidhane, and M. Khatib. "Profile of Urinary Tract Infection in a Rural Tertiary Care Hospital: Two-Year Cross-Sectional Study." Journal of Datta Meghe Institute of Medical Sciences University. 2019; 14( 1): 22-26.

59. Gade, S.A., S.N. Chari, and A. Chalak. "Use of Mini-CEX as a Teaching-Learning Method in Physiology for Undergraduate Medical Students." National Journal of Physiology, Pharmacy and Pharmacology 2017; 7(5): 482-85.

60. Jagzape, A.T., T. Jagzape, and A. Rawekar. "Patient-Based Integrated Teaching Program with the Inclusion of Psychomotor and Affective Domains." Nat. J. Physiology, Pharm and Pharmac. 2017; 7(8): 788-92.

61. Pratit P. Vyas, Amol L. Bhave. Evaluation of Scientific and Ethical Status of Drug Promotional Literatures (DPLs) for Ethical Medicinal Drug Promotion. International Journal of Current Research and Review. 2018;10(5):30-35. 